\title{
O conhecimento científico e o tribalismo: a emoção do cotidiano na pós-modernidade
}

\author{
Humberto Ivan Keske \\ Doutor em Comunicação Social (Pontifícia Universidade do Rio Grande do Sul) \\ Professor titular na Universidade Feevale \\ humberto@feevale.br \\ Mary Sandra Guerra Ashton \\ Doutora em Comunicação Social (Pontifícia Universidade do Rio Grande do Sul) \\ Professora na Universidade Feevale \\ marysga@feevale.br
}

\begin{abstract}
Resumo Esse artigo propõe uma leitura das ondulações sociais observadas entre a modernidade e a pós-modernidade. Tem como objetivo compreender os laços sociais que se revelam e se estabelecem a partir da chamada pós-modernidade, criando condições para a investigação e criação de novas possibilidades de produção do conhecimento científico. Para tanto, se fundamenta nas noções desenvolvidas por Maffesoli e Morin para a análise da diversidade social, através da revisão das estratégias que estruturam esse espaço. Por se tratar de uma leitura bibliográfica das principais obras de Maffesoli no tocante à temática proposta, pretende, ainda, contribuir para os que queiram se aventurar nesse universo teórico.
\end{abstract}

Palavras-chave: pós-modernidade; modernidade; conhecimento científico; laços sociais; tribalismo.

\section{Introdução}

T NSERIDA Num CONTEXto Pós-Moderno, a sociedade contempoIânea se encontra composta por elementos contraditórios que convivem mutuamente; ou seja, o arcaico e tecnológico, o individualismo e a coletividade, a racionalidade e a emotividade se entrelaçam e se confrontam na formação do corpo social. A presença de conflitos, a urgência do presente e a hegemonia da imagem fazem parte dessa gestação intensa que se transforma na responsável pelo novo desenho da atual sociedade. O cotidiano passa a ser formado por pequenos detalhes, contatos, emoções, laços que unem os seres humanos para a ordem ou a desordem, numa vivência infindável de acontecimentos diários que encontram em Maffesoli, estudioso incansável das questões sociais, o necessário aprofundamento teórico a respeito das manifestações da sociedade pós-moderna.

$\mathrm{Na}$ emergência desse ethos descentralizado, o autor percebe que a gênese do conhecimento nasce com a prática do relativismo científico, da complexidade e da articulação entre diferentes fatores colocados em permanente contato e contraste. Nestes termos, desenvolve a ideia de que se deve buscar justamente o afastamento do cientificismo de inspiração positivista e voltar-se para o banal, ou seja, para a experiência do cotidiano, para a leitura daquilo que é vi- 
vido em seus aspectos mais triviais, dando a devida atenção às novas configurações emotivas.

A noção de tribalismo passa a fazer parte desse contexto, (re)significando antigos valores que irão repercutir num retorno de determinados elementos que a modernidade julgava ultrapassados e arcaicos. Tais aspectos, entretanto, passam a ser fundamentais para a compreensão da atual socialidade, proporcionando um humanismo muito forte e levando a uma verdadeira solidariedade juvenil, ou seja, uma nova fraternidade. Inclusive, para Maffesoli (1988, p. 19), pode-se pensar no tribalismo como um novo humanismo, mais completo e rico, capaz de misturar prazeres e desprazeres nesse ambiente desafiador chamado sociedade.

Em função disso, na busca da compreensão para as inquietantes questões que envolvem a teia social no seu dia-a-dia, este artigo se ocupa da problematização dos novos comportamentos descritos na passagem da modernidade para a pós-modernidade. A partir das noções desenvolvidas por Maffesoli em seu diálogo com Morin, procura-se, então, visualizar esse conjunto criativo de instigantes possibilidades de produção de conhecimento. Por se tratar de uma leitura bibliográfica das principais obras do autor no tocante à temática proposta, pretende, ainda, contribuir para os que queiram se aventurar nesse universo teórico.

\section{Para um novo conhecimento: a razão sensível da ciência nascente}

$\mathrm{Na}$ Europa, no decorrer do século XVII, o conhecimento científico veio a se constituir em uma esfera distinta. As condições sócio-históricas da sua gestação foram as transformações que determinaram a passagem do mundo feudal ao mundo moderno, mediante o florescimento cultural e civilizacional do Renascimento, o que provocou o triunfo do capitalismo e a ascensão e consolidação da burguesia. No embalo destas mesmas transformações, rompe-se a grande unificação cultural mantida sob a égide teológica: a cisão luterana e calvinista. Assim, o retorno ao pensamento profano e as fontes de inspiração gregas permitem o renascimento da especulação filosófica e, segundo Morin, também o florescimento das técnicas e das artes.

O renascimento é um fenômeno de intenso 'calor' cultural, no qual as rígidas barreiras entre artes, filosofia e ciência não estão ainda formadas ou fechadas. Os espíritos originais são diletantes universais, humanistas interessados em tudo. O encontro com o pensamento técnico acontecerá nos espíritos mais autônomos, transportados pela grande agitação cultural. São artistas, pensadores, criadores, artesãos, inventores, a exemplo de Leonardo; ou pensadores/ bricoleurs, tipo Galileu. (Morin, 1998, p. 73)

Em termos políticos, "ocorre a formação das novas repúblicas urbanas e mercantis, os Estados-nação da Inglaterra, França e Espanha” (Morin, 1998, p. 7273). Entretanto, não será na casta dos clérigos ou dos universitários que se formará a nova efervescência cultural. Enquanto a destruição de um mundo (a revolução copernicana) determinava uma crise paradigmática profunda, a ciência nascente elaborava os princípios e métodos que iriam construir o novo paradigma de um conhecimento doravante separado da política, da religião, da moral e mesmo da filosofia. Sua regra profunda libera o saber de todo o juízo de valor e destina-o exclusivamente à finalidade do conhecimento; seu saber organiza-se com base num cientificismo unicamente empírico-racional, desviando-se das verdades triviais ocultas pelo cotidiano.

O conhecimento científico emergente estabelece exigências de precisão e exatidão, que as crendices populares não mais poderiam lhe oferecer. Assim, a cientificidade procurou libertar-se, cada vez mais, das normas e pressões sociais. As descobertas de comprovação científico-acadêmicas fizeram proliferar trabalhos e estudos no mundo inteiro, autonomizando, institucionalizando e compartimentando a ciência cada vez mais. As sociedades científicas multiplicaram-se e, no século XIX, a ciência instalou-se na universidade, criando aí os seus departamentos e laboratórios.

Em torno de 1840, o termo 'scientist' aparece na Inglaterra, e a ciência profissionaliza-se. No século XX, ela se implantará no coração das empresas industriais e depois no aparelho do Estado. O conhecimento científico domina cada vez mais o desenvolvimento social, econômico e técnico, mas se torna cada vez mais integrado política, administrativa, social e tecnicamente. O conhecimento científico é certamente cada vez mais puro, desinteressado especulativo, mas, ao mesmo tempo, é mais operacional, manipulador e manipulado. (Morin, 1998, p. 77)

Entretanto, os conceitos científicos extraídos da experiência social não se separam totalmente da vida comum, até porque no interior de toda a teoria científica "há postulados metafísicos ou ideológicos, e ainda, mais profundamente, paradigmas que a ligam como um cordão umbilical à cultura da qual é originária e à história na qual nasce e ganha consistência" (Morin, 1998, p. 78). As teorias científicas e as ideologias políticas acabaram por transformar, pelo próprio processo de secularização e laicização, os an- 
tigos mitos, como os do panteão greco-romano, em entidades estéticas, poéticas, artísticas ou musicais, multiplicando-se os universos tecidos a partir de substâncias semi ou irreais e imaginárias e os reintroduzindo no meio científico por meio da literatura, onde a cultura mitológica reina de maneira singular, ganhando existência real,

Por tais razões, Morin (1999) busca uma nova sociologia, mais adequada à complexidade das relações sociais e da cultura e que possa articular o saber científico à sua outra face, humana e não-comprovável por processos de precisão matemática. Busca, também, um método que dê conta desse novo tipo de investigação, nem tão racionalista, nem tão mágica a ponto contentar-se com suposições infundadas.

A necessidade de se pensar em uma metodologia formada 'a partir de' ou 'através de' saberes nômades, cuja permeabilidade articula diferentes campos de saber, desde o enciclopédico até os saberes do cotidiano, nos serve de fio condutor para introduzir a problemática proposta por Maffesoli (1995). Em diversos momentos de suas obras, seja em palestras, seja em seminários ou ensaios críticos, a noção de pós-modernidade por ele desenvolvida vem contribuindo para a integração, no pensamento racional cartesiano dominante, de parâmetros humanos como a instância do onírico, do lúdico e do imaginário, criando assim a ideia de uma razão sensível.

\section{Dualidade Social: laços sociais definidos pelo compartilhar}

Preocupado com os rumos do século XXI, Maffesoli (2000b) questiona a noção de cultura global. Problemática e conflituosa, para o sociólogo a globalização não passa de uma falsa ideia dos tempos modernos, uma vez que os diferentes Estados-nações continuam afirmando antigos valores, crenças, culturas e religiões. Tais aspectos o fazem pensar na ideia de uma aparente globalização, ou, dito de outra forma, uma globalização imaginada ou imaginária.

Por outro lado, se assiste a uma reafirmação das velhas crenças e ideologias por parte das nações e a explosão de grupos sociais formados por tribos, uma das principais características da atualidade. A sociedade se mantém unida por meio de laços sociais que se estabelecem, cada vez mais, pela comunhão emocional, pelo simples compartilhar trivializado. Ou seja, sob a égide do cotidiano, "a sociedade é formada por um conjunto de relações interativas, feito de afetos, emoções, sensações que constituem, stricto sensu o corpo social" (Maffesoli, 1996, p. 73). O compartilhar, como interação, acontece quando se pode comungar um afeto. Assim, a correspondência do sentimento, do sensível, não trata do número de vezes ou da quantidade de pessoas no processo comunicacional, mas, sim, da essência, da paixão que esses indivíduos comungam entre si.

Segundo o autor, as cidades contemporâneas são povoadas por tribos, o que implica uma pluralidade de origens, comportamentos e identidades distintas. A sociedade não nasce da redução da diversidade a um elemento centralizador único, mas da conjunção de elementos díspares. O zen, o candomblé e os valores africanos, por exemplo, estão presentes nas ações do cotidiano da sociedade pós-moderna: na maneira de vestir, de festejar, de se alimentar. Características da pós-modernidade, a lógica da união e o seu apelo para o coletivo é algo que se vive cotidianamente, embora a intelligentsia - acadêmicos, políticos, imprensa - permaneçam dominados pelo pensamento racional moderno.

Assim, a pós-modernidade não se fundamenta em distinções precisas e simples, mas em uma complexidade que integra tudo, inclusive a instância do paradoxal. Desse modo, estaríamos retornando ao mito nietzschiano de Dionísio, momento em que um novo paradigma cultural está em gestação, deixando para trás os traços da chamada modernidade e adotando um ponto de vista mais emotivo, hedonista em relação ao mundo.

Conforme Maffesoli (2004a), cada sociedade, em um dado momento histórico, tem uma figura emblemática forte. Na modernidade, foi Prometeu, o deus do trabalho, da razão, da seriedade, mas houve uma fadiga, um desgaste, uma saturação pela superexposição. A pós-modernidade assiste ao retorno de uma figura emblemática em oposição a Apolo: Dionísio, que representa a desordem, a festa, e, sobretudo, a transgressão. A influência dionisíaca na sociedade, com o desenvolvimento do hedonismo, implica uma importância exagerada concedida ao corpo, aos prazeres. Trata-se de uma tendência mundial, no qual o corpo adquiriu um valor em si mesmo: a cirurgia estética é um exemplo dessa tendência. "Queremos permanecer jovens, falar como jovens, nos vestir como jovens, ter um corpo como o dos jovens" (Maffesoli, 2004b).

O mundo retorna aos valores que a modernidade julgava enterrados, ou seja, as múltiplas dicotomias entre razão e progresso. Motor da organização das sociedades desde o século XVIII, o jogo de oposições vai dando lugar ao prazer e à emoção entre as novas gerações. Para Maffesoli (2000b), tais aspectos repercutem profundamente nessa nova tendência que aponta para uma certa desafeição/desafeto pelas grandes instituições sociais, como os partidos políticos e os sindicatos. Nas grandes cidades, por exemplo, cada vez mais as pessoas estão se reagrupando em torno de microtribos na busca por novas formas de solidariedade, que não podem ser encontradas, necessariamente, nas grandes instituições sociais habituais que deveriam ser referência para o indivíduo. 
A modernidade é entendida pelo autor como o grande modelo europeu do pensamento racional. Corresponde aos séculos XVIII, XIX e XX até os anos 1960, momento de grandes transformações políticas, sociais e culturais no mundo ocidental. De acordo com o modelo de vida europeu, a vida social é organizada de forma racional. O grande valor é a razão, onde tudo o mais se torna previsível, ideal. As escolas e a saúde pública, por exemplo, são organizadas de modo uniforme, por intermédio de diversas políticas consensuais.

Nesses termos, a modernidade está apoiada sobre uma grande obsessão: o progresso desenfreado, linear, contínuo. A ênfase está no futuro. O passado inexiste, a referência do presente é o amanhã. Para Maffesoli, partimos de um ponto de barbárie e vamos chegar a um ponto da civilização absoluta, caracterizado pelos valores judaico-cristãos que consideram a existência de um paraíso e que esse local representa o fim ideal de toda a humanidade. Segundo o autor, este modelo racional, que começou nos anos 1960 e 1970, experimentou uma crescente saturação a partir dos anos 1980, culminando com uma nova (re)visão de mundo a partir dos anos 1990.

A educação centralizada não funciona mais, há movimentos beneficentes que se desenvolvem para compensar a disfunção da saúde pública. Toda uma série de fenômenos que, para mim, são tribais. Não é mais uma organização jacobina, piramidal e muito acional que organiza o social. Ao contrário, o comando desse social começa a ser tomado por baixo, pelas microtribos, a partir da emoção, do afeto, e não da razão. A ênfase está no presente: é preciso viver aqui e agora. (Maffesoli, 2000b, p. 67)

É nesse sentido que o advento da pós-modernidade esboça o início do que o autor chama de "A sociedade da imagem", ou seja, a fragmentação do social começa, gradualmente, a desintegrar nossas representações do real, resultando em uma fragmentação generalizada: de identidades, de sociedades, de culturas. Espaço tenso e ainda em formação, a necessidade do consumo crescente de objetos, de sinais e de imagens constitui um espaço que transforma as concepções de sonho e de realidade, fazendo com que a sociedade se torne prisioneira de um universo simbólico de opacidades crescentes e de realidades completamente diversas entre si.

\section{Pós-modernidade: a simbiose dos contrastes}

Maffesoli traz a noção de pós-modernidade como sendo "a sinergia de fenômenos arcaicos e do desenvolvimento tecnológico" (2001, p. 21), ou seja, a confluência de aspectos tais como o retorno do local, a importância da tribo, a bricolagem mitológica, o estilo barroco, a hegemonia do presente, a supremacia da imagem, fazem parte deste espectro. $\mathrm{O}$ autor enfatiza que nesse espaço de descontinuidades, os indivíduos ou grupos de indivíduos estão voltados para "tudo aquilo que remete a um sentimento de pertencimento reforçado" (Maffesoli, 2001, p. 22).

Reaproveitando elementos enraizados pela cultura, esses indivíduos ou grupos de indivíduos fazem uso de um constante jogo de contrastes, como o passado e o presente, para produzirem um imaginário social cada vez mais rico e difuso. Promovem a construção, desse modo, de um cenário de realidades contemporâneas que se aglutinam em torno do cotidiano, revestindo-o de uma nova vida, de um novo significado. $O$ processo em gestação deixa de ser marcado pelo fim clássico do período anterior, mas, ao contrário, constitui uma composição inusitada que convive com as bases retiradas do passado. A esse artifício de reciclagem, o autor chama de pós-modernidade, ou seja, "saturação-recomposição" (Maffesoli, 2001, p. 21).

Para o autor, a pós-modernidade é o local onde se criam novas formas de partilha emocional, refletindo o sentimento coletivo de parte da sociedade com relação aos valores enraizados de territorialidade geográfica, representada pelo Estado-nação e pertencimento familiar, característico dos laços sanguíneos. Enfatiza a ideia do lugar, cuja base de pertencimento é a da união emocional, fundada nas coisas cotidianas tais como a tribo urbana com a qual se identifica, os usos e costumes, os idiomas, a gastronomia, ao contrário de um vínculo abstrato e racional, impostamente colocado como mediador entre o indivíduo e a sociedade, como até então vinha sendo trabalhado pela modernidade.

Desse modo, assiste-se a uma "solidariedade social elaborada a partir de atrações, de repulsões, de emoções e de paixões" (Maffesoli, 1996, p. 15). Esta tensão transforma as diversas instituições sociais já fragmentadas em mais abstratas e desconectadas, nascendo a necessidade de solidariedade autêntica e de proteção, elementos fundadores do tribalismo, que caracterizam todo o conjunto social. O tribalismo, para Maffesoli, pode ser entendido como "um processo de (des)individualização, da saturação da função que lhe é inerente e da valorização do papel que cada pessoa é chamada a representar dentro dela" (1988, p. 108). As pessoas podem passar a representar diferentes papéis, de acordo com o grupo a que estão inseridos naquele momento e de acordo com sua preferência; não se trata de percorrer uma lógica da identidade. São sujeitos de uma história em andamento, que se debruçam em assumir a cada dia o seu lugar nas diversas peças do teatro.

Por outro lado, Maffesoli (2001) destaca a importância da aparência individual, na qual recai a trágica superficialidade de aceitação, sobre a unidade da tribo. A representação dessa individualidade, essa teatralida- 
de na busca de uma adequação em relação ao grupo, é também um meio de autoconhecimento e, nesse sentido, de aproximação da comunidade. $\mathrm{O}$ culto ao corpo e o jogo das aparências servem de cimento para essa incursão. Trata-se de uma sociologia dos sentidos que assinala o seu valor, porque se inscrevem numa cena ampla, onde cada um é ator e, ao mesmo tempo, espectador. Ou seja, os diversos nichos, fundados por afinidades, para o bem ou para o mal, possuem igual estrutura, onde se cultivam a partilha do sentimento, afetos mútuos e paixões. Pode-se falar de transfigurações das verdades absolutas, das ideologias, a que Maffesoli (2001, p. 23) chama de "bricolagem mitológica, autônoma e particularizada, que demarca o território real ou simbólico, para expressar o seu modo de representação; o que prevalece é perder-se no outro e em função do outro, onde a lei é o outro".

Assim, a pós-modernidade, para Maffesoli (1996, p. 15), "é como uma colcha de retalhos, que é feita de elementos totalmente diversos, mas que estabelecem entre si interações constantes e contínuas". A fusão temporal é a forma de expressão que promove a comunhão sob o domínio daquilo que se faz presente na realidade cotidiana. Através do uso dos extremos, dos contrastes, do antigo e do atual, características do estilo barroco, a pós-modernidade gera novos significados aos mesmos conceitos. Conforme o autor, o que ocorre é a barroquização das sociedades contemporâneas, ou seja, "é a explosão dos valores sociais, o relativismo ideológico, a diversificação dos modos de vida, que engendram essa barroquização da existência, com a qual estamos confrontados" (Maffesoli, 1996, p. 187). Até mesmo, percebe o "Barroco como um tipo de sensibilidade" (Maffesoli, 1996, p. 188); e a barroquização como uma reformulação da própria existência, tendo em vista esse mundo das aparências, ao qual nenhum domínio da vida social escapa.

A teatralidade favorece o que é vivido 'hic et nunc', o que recusa a transferência de prazer. Há, no artifício e nos fantásticos barrocos, um imanentismo evidente cuja virtude essencial é deter a corrida do tempo. Reconhecendo a aparência pelo que ela é, não se procura nenhum "mundo anterior", seja qual for. [...] A conjunção do ambiente e da aparência empenha-se em fazer com que o artifício amável, ornado de múltiplos atrativos, torne-se suportável. É, portanto, um ajustamento a esse mundo que é induzido pelo frívolo jogo das aparências (Maffesoli, 1996, p. 192).

Conforme Maffesoli (2001), a pós-modernidade, "é feita de afetos, de sentimentos, de excessos que nos dirigem mais do que os dominamos" (Maffesoli 2001, p. 24). Trata-se do contágio, da contaminação, na estranha pulsão que leva a imitar o outro e que se exprime "nas efervescências festivas, nas atmosferas emocionais, em todos os agrupamentos excessivos em que o indivíduo se perde na tribo" (Maffesoli, 2001, p. 25), a fim de tornar o mundo suportável. Ou seja, o individual se apaga para dar lugar ao coletivo, em que cada um se integra a um conjunto que lhe permite ao mesmo tempo viver e entrar em correspondência com os outros, numa perspectiva de que alguém só existe graças e em função dos outros, em uma nova ordem comunicacional. Cria-se uma realidade imaginária, que reflete o sentimento comum da sociedade.

O presenteísmo, outro elemento que caracteriza a pós-modernidade para Maffesoli (2000a, p. 61-67), por intermédio da junção do passado, do presente e do futuro, é traduzido, pelo autor, como a eternidade. Essa tríade temporal coloca as pessoas em harmonia com o mundo, por meio da repetição ritual e ritmada, como uma espécie de eternidade ou a 'duração concreta' das imagens, as imagens suspensas no tempo. $\mathrm{Na}$ vida cotidiana pós-moderna, "só importa o instante em que se pode resumir a eternidade em sua plenitude" (Maffesoli, 2000a, p. 51). Ou seja, não importa se são bons ou maus momentos, mas se eles foram vividos de maneira intensa, qualitativa e coletiva. $\mathrm{O}$ que predomina é um presente que se vive com outros em um dado lugar; e é isso que vai contaminar as representações. Assim, por intermédio da saturação do espaço-tempo, delineia-se a busca do sentido no próprio ato presentificado pela existência. A decadência do ideal, do longínquo, encerra a maneira de dizer o presente e o instante, vividos em toda sua intensidade. O prazer é vivido no presente, não sendo mais adiado para um futuro distante.

Na pós-modernidade, segundo Maffesoli (2000a), assiste-se ao retorno da imagem, que adquire valor relevante na formação do sujeito e da sociedade. Ou seja, local onde tudo e todos devem ser espetacularizados, isto é, deixar-se ver em espetáculo. Assiste-se a um (re) encantamento do mundo, por meio da tecnologia. Trata-se, aqui, de um mundo imaginal, entendido como uma maneira de ser e de pensar perpassados pela imagem, pelo simbólico, pelo imaterial, entendidos como vetores primordiais do vínculo social. $\mathrm{O}$ autor observa que a pós-modernidade contém um apanhado de elementos que tratam de contribuir para o entendimento da socialidade do cotidiano contemporâneo. Sublinha que os valores da cultura se transformam e retornam à sociedade, estabelecendo um novo ethos vinculado ao processo de tribalização, agora expresso em suas mais variadas representações imagéticas.

A noção de pós-modernidade, nessa perspectiva, procura explorar as diferentes ligações entre mundos, regulando e organizando nossas representações da realidade e recriando/reproduzindo nosso imaginário e nossas mais secretas fantasias, sejam de consumo, de poder, de auto-estima, de referência. Novamente, a ideia da simbiose de elementos opostos e formantes da socialidade se apresenta, ajustando-se à preocupação não mais com o territorial, mas com o simbólico 
da cultura, o que repercute num retorno à natureza, à religiosidade e ao prazer dos sentidos e na sua adequação ao desenvolvimento tecnológico utilizado pelo policulturalismo das megalópoles, repletas de formas comunicacionais cotidianas. Em função disso, Maffesoli (1985) percebe uma conexão existente entre o interesse pelo presente, ou seja, a vida diária, e uma estética do imaginário, que repercute em uma determinada comunidade, na forma da emoção compartilhada; ou seja, da união tribal. Neste imaginário coletivo, pertencer a uma determinada cultura implica em reconhecer não mais os limites imóveis do que nos foi dado, mas sim que fazemos parte de um esboço em vias de construção.

\section{Considerações Finais}

O diálogo entre Maffesoli e Morin traz à tona a proposta de uma nova socialidade, entendida como o espaço do contato entre diferentes identidades; das trocas entre culturas e da negociação entre os indivíduos envolvidos no processo de re-articulação do conhecimento. Desse local em permanente transformação, emerge um novo laço social emocional marginal, que promove uma reorganização da estrutura do saber baseada em uma articulação da ciência antropossocial com a ciência da natureza, do conhecimento científico-acadêmico com a cotidianidade da vida humana mundana, repleta de mitos, ritos, superstições, saberes populares e ditos vulgares que foram banidos da academia durante séculos.

Ao questionar o cientificismo, Maffesoli aproxima-se de Morin estabelecendo as bases de uma metodologia que não faz parte, estritamente, dos livros acadêmicos, bibliotecas, teorizações, racionalizações. Trata-se de um método cuja impureza do olhar contamina o investigador e a própria investigação com cores e matrizes mais reais e verdadeiras, contribuindo para enriquecer a multidisciplinaridade em todos os campos do conhecimento, pela necessidade de uma visão mais complexa da realidade e de uma reforma de pensamento complexo capaz de romper com as simplificações, as reduções e os purismos academicistas.

Pervertendo a ordem estrutural do conhecimento científico, a noção de tribalização torna relevante o não-percorrido caminho do saber vulgar, da cotidianidade, do comunitário, do botequim e da conversa de bar. Ou seja, tudo pode se tornar uma fonte de conhecimento, mostrando matizes coloridas até então não percebidas pelo cientificismo de inspiração positivista. Tal procedimento, na opinião do autor, serve como base para uma análise mais adequada do espaço social em permanente transformação.

Consumidoras e produtoras de um novo tipo de conhecimento, as tribos urbanas são formadas, em sua maioria, por grupos de jovens em que a harmonia de ideias e estilos de vida os diferenciam da cultura dominante. Propõe algo libertador, que lhes oferece a sensação de serem ou estarem diferentes em relação a um todo homogeneamente constituído. O estilo de vida é o centro da identidade da tribo, composto, muitas vezes, por roupas, adornos corporais, crenças, valores, atitudes, hábitos e formas de comportamento que são os emblemas mais visíveis de um participante. A adesão ao grupo significa fidelidade ao espírito e à filosofia da contemporaneidade, conforme reitera Maffesoli (1988, p. 194): "a constituição de microgrupos, das tribos que pontuam a espacialidade se faz a partir do sentimento de pertença, em função de uma ética especifica e no quadro de uma rede de comunicação".

Até mesmo, para ele (1988, p. 160), esta é a matriz com base na qual se desenvolvem todas as representações em que a elaboração e a divulgação das opiniões devem muito ao mecanismo de contágio do sentimento, ou das emoções vividas em comum, projetadas em figuras míticas que permitem manifestar uma estética que serve de receptáculo à expressão do conjunto, ou seja, local de onde emerge um forte sentimento grupal. Trata-se da vontade de estar-junto, em que o que importa é o compartilhamento de emoções em comum, mediante formas de empatia onde a única preocupação é com o tempo presente que é vivido coletivamente. Por tais razões, defende que o estilo de vida não é uma coisa inútil, pois é isso mesmo o que determina a relação com a alteridade: da simples sociabilidade (polidez, rituais, civilidade, vizinhanças) à socialidade mais complexa (memória coletiva, simbólica, imaginário social). Ora, como apreender o estilo de uma época se não for através do que se deixa ver? (Maffesoli, 1988, p. 160).

Nessa perspectiva, a pós-modernidade conforme definida pelo autor, remete à conjunção de elementos muito diversos, como a mestiçagem e a (re) união de oposições; a razão versus a emoção. Trata-se de uma estética não apenas funcional, na qual não há uma verdade única, mas sim a convivência de uma multiplicidade de culturas e conceitos que habitam o espaço dinâmico da socialidade. Vale lembrar que "o social repousa na associação racional de indivíduos que têm uma identidade precisa e uma existência autônoma; a socialidade, por sua vez, se fundamenta na ambigüidade básica da estruturação simbólica" (Maffesoli, 2000a, p. 135).

Desse modo, valoriza as banalidades que desacreditam todo o triunfalismo progressista e positivista para dar passagem às dimensões imaginárias que estão presentes na sociedade como um todo, ressurgindo no tempo e no espaço. Por isso, Maffesoli (1988) percebe a importância de apreender os contornos sociais e compreender as suas manifestações. Ou seja, na ótica do comum, da comunidade, da coletividade, os aspectos emocionais são compartilhados de todos para todos. 


\title{
Referências
}

MAFFESOLI, Michel. O conhecimento comum: compêndio de Sociologia Compreensiva. São Paulo: Brasiliense, 1985. MAFFESOLI, Michel. O tempo das tribos. Rio de Janeiro: Forense-Universitária, 1988.

MAFFESOLI, Michel. A contemplação do mundo. Porto Alegre: Artes \& Ofícios, 1995.

MAFFESOLI, Michel. No fundo das aparências. Petrópolis, Vozes, 1996.

MAFFESOLI, Michel. Sobre o nomadismo, vagabundagens pós-modernas. Rio de Janeiro: Record, 2000a.

MAFFESOLI, Michel. A transfiguração do político, a tribalização do mundo. Porto Alegre: Sulina, 2000b.

MAFFESOLI, Michel. O eterno instante. Lisboa: Instituto Piaget, 2001.

MAFFESOLI, Michel. A parte do diabo. Rio de Janeiro: Record, 2004a.
MAFFESOLI, Michel. Palestra. In: SEMINÁRIO INTERNACIONAL DE COMUNICAÇÃO, IMAGINÁRIO SOCIAL E PÓS-MODERNIDADE, Porto Alegre, out. 2004b.

MORIN, Edgar. O Método III: o conhecimento do conhecimento. Porto Alegre: Sulina, 1999.

MORIN, Edgar. O Método IV: As idéias: habitat, vida, costumes, organização. Porto Alegre: Sulina, 1998.

MORIN, Edgar. Política de civilização e problema mundial. Revista Famecos, Porto Alegre, n. 5, p. 07-13, dez. 1996.

SUBIRATS, Eduardo. Transformaciones de la cultura moderna. In: CASULLO, Nicolas (Org.). El debate modernidad/pós-modernidad. Barcelona: Bosch Casa Editorial, 1985.

\section{Scientific knowledge and tribalism: the thrill of daily life in postmodern times}

\begin{abstract}
:
This article proposes a reading of the social ripples observed between modernity and post-modernity. Aims to understand the social ties revealed and established from the so-called post-modernity, and that generated conditions for research and creation of new possibilities of scientific knowledge production. For this purpose, it is based on concepts developed by Morin and Maffesoli for the analysis of social diversity, through the revision of strategies that structure this field. Since it is a reading literature of author's main works that are related to the proposed thematic, it also intends to help those who want to venture into this theoretical universe.
\end{abstract}

Keywords: post-modernity; modernity; scientific knowledge; social ties; tribalism.

\section{Conocimiento científico y tribalismo: la emoción de la vida cotidiana en la época postmoderna}

\begin{abstract}
Resumen:
Este artículo propone una lectura de las repercusiones sociales observadas entre la modernidad y la posmodernidad. Tiene como objetivo entender los lazos sociales que si revelan y se establecen desde la llamada posmodernidad, en el que genera condiciones para la investigación y la creación de nuevas posibilidades de producción del conocimiento científico. Para ello, se basa en los conceptos desarrollados por Maffesoli y Morin para el análisis de la diversidad social, a través de la revisión de las estrategias que estructuran ese espacio. Se trata de una lectura de la bibliografía de importantes obras del autor con relación al tema propuesto, pretende, además, contribuir con los que quieren aventurarse en éste universo teórico.
\end{abstract}

Palabras clave: postmodernidad; modernidad; conocimiento común; lazos sociales; tribalismo.

Data de recebimento do artigo: 20-10-2010

Data de aprovação do artigo: 16-01-2011 